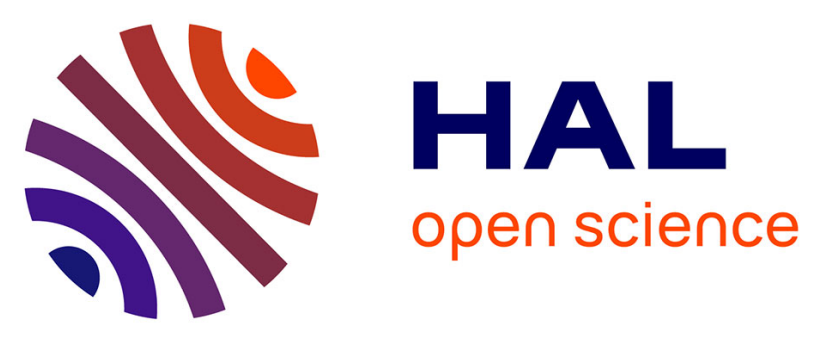

\title{
Paradoxically, iron overload does not potentiate doxorubicin-induced cardiotoxicity in vitro in cardiomyocytes and in vivo in mice
}

Charles Guenancia, Na Li, Ahmed Habbout, Olivier Hachet, Eve Rigal, Yves Cottin, Patrick Dutartre, Luc Rochette, Catherine Vergely

\section{To cite this version:}

Charles Guenancia, Na Li, Ahmed Habbout, Olivier Hachet, Eve Rigal, et al.. Paradoxically, iron overload does not potentiate doxorubicin-induced cardiotoxicity in vitro in cardiomyocytes and in vivo in mice. Toxicology and Applied Pharmacology, 2015, 284 (2), pp.152-162. 10.1016/j.taap.2015.02.015 . hal-03434181

\section{HAL Id: hal-03434181 \\ https://u-bourgogne.hal.science/hal-03434181}

Submitted on 18 Nov 2021

HAL is a multi-disciplinary open access archive for the deposit and dissemination of scientific research documents, whether they are published or not. The documents may come from teaching and research institutions in France or abroad, or from public or private research centers.
L'archive ouverte pluridisciplinaire HAL, est destinée au dépôt et à la diffusion de documents scientifiques de niveau recherche, publiés ou non, émanant des établissements d'enseignement et de recherche français ou étrangers, des laboratoires publics ou privés. 


\title{
Paradoxically, iron overload does not potentiate doxorubicin-induced
}

\section{cardiotoxicity in vitro in cardiomyocytes and in vivo in mice}

\author{
Charles Guenancia ${ }^{1}, \mathrm{Na} \mathrm{Li}^{2}$, Ahmed Habbout ${ }^{3}$, Yves Cottin ${ }^{4}$, Patrick Dutartre ${ }^{5}$, Carmen \\ Garrido $^{6}$, Luc Rochette ${ }^{7}$, Catherine Vergely ${ }^{8}$
}

Address correspondence to: Pr. Catherine VERGELY, LPPCM, Inserm UMR866, Facultés de Médecine et Pharmacie, 7 Bd Jeanne d'Arc, 21000 Dijon, France

Telephone: (+33) 380393 460, Fax: (+33) 380393293

Email: cvergely@u-bourgogne.fr

Funding: This work was supported by grants from the French Ministry of Research, from the Institut National de la Santé et de la Recherche Médicale (INSERM), from the Société Française de Cardiologie, from the Regional Council of Burgundy and from the Association de Cardiologie de Bourgogne (ACB).

Conflict of interest: On behalf of all authors, the corresponding author states that there is no conflict of interest.

Keywords: Doxorubicin, iron overload, cardiotoxicity, oxidative stress, cell proliferation

${ }^{1}$ INSERM UMR866, LPPCM, Faculties of Medicine and Pharmacy, University of Burgundy, and University Hospital, Cardiology Department, Dijon, FRANCE. This author takes the responsibility for all aspects of the reliability and freedom from bias of the data presented and their discussed interpretation.

2 INSERM UMR866, LPPCM, Faculties of Medicine and Pharmacy, University of Burgundy, Dijon, FRANCE. This author takes the responsibility for all aspects of the reliability and freedom from bias of the data presented and their discussed interpretation.

${ }^{3}$ INSERM UMR866, LPPCM, Faculties of Medicine and Pharmacy, University of Burgundy, Dijon, FRANCE; This author takes the responsibility for all aspects of the reliability and freedom from bias of the data presented and their discussed interpretation.

${ }^{4}$ INSERM UMR866, LPPCM, Faculties of Medicine and Pharmacy, University of Burgundy, and University Hospital, Cardiology Department, Dijon, FRANCE; This author takes the responsibility for all aspects of the reliability and freedom from bias of the data presented and their discussed interpretation.

${ }^{5}$ INSERM UMR866, LPPCM, Faculties of Medicine and Pharmacy, University of Burgundy, Dijon, FRANCE; This author takes the responsibility for all aspects of the reliability and freedom from bias of the data presented and their discussed interpretation.

${ }^{6}$ INSERM UMR866, University of Burgundy, Dijon, FRANCE

${ }^{7}$ INSERM UMR866, LPPCM, Faculties of Medicine and Pharmacy, University of Burgundy, Dijon, FRANCE; This author takes the responsibility for all aspects of the reliability and freedom from bias of the data presented and their discussed interpretation.

${ }^{8}$ INSERM UMR866, LPPCM, Faculties of Medicine and Pharmacy, University of Burgundy, Dijon, FRANCE; This author takes the responsibility for all aspects of the reliability and freedom from bias of the data presented and their discussed interpretation. 


\section{Abstract:}

Background: Doxorubicin (DOX) is known to induce serious cardiotoxicity, which is believed to be mediated by oxidative stress and complex interactions with iron. However, the relationship between iron and DOX-induced cardiotoxicity remains controversial.

Methods: Firstly, we evaluated in vitro in cultured EMT-6cancerous cells and in H9c2 cardiomyocytes the effects of DOX, in combination with dextran-iron, on cell viability. Secondly, we used an in vivo murine model of iron overloading (IO) in which male C57BL/6 mice received a daily intra-peritoneal injection of dextran-iron $(15 \mathrm{mg} / \mathrm{kg})$ for 3 weeks (D0D20) and then (D21) a single intra-peritoneal injection of $6 \mathrm{mg} / \mathrm{kg}$ of DOX. We evaluated cardiac function with echocardiography, myocardial gene expression, nitro-oxidative stress levels and iron status

Results: While DOX $(1 \mu \mathrm{M})$ significantly decreased cell viability in EMT-6 or H9c2, dextraniron $(125-1000 \mu \mathrm{g} / \mathrm{mL})$ alone did not and, in combination with DOX, did not impair DOX cytotoxicity. In mice, IO alone resulted in cardiac hypertrophy (+22\%) and up-regulation of $\beta$-myosin heavy-chain expression $(\times 2.6, \mathrm{p}=0.001)$. In myocardial tissue, electron spin resonance spectroscopy revealed an increase in nitro-oxidative stress in IO groups. At D30, there was a significant decrease in left-ventricular ejection fraction (LVEF) in all groups of DOX-treated mice. In IO mice treated with DOX, the LVEF fall was not exacerbated and there was no increase in atrial-natriuretic peptide mRNA cardiac gene-expression.

Conclusions: IO did not impair the capacity of DOX to decrease cancer cell viability and did not result in a significant increase in DOX cardiotoxicity in cardiomyocytes and in mice. 


\section{Non-Standard Abbreviations:}

ANP: atrial natriuretic peptide, AU: arbitrary unit, $\beta$-MHC: beta-myosin heavy chain, BNP: brain natriuretic peptide, cDNA: complementary deoxyribonucleic acid, DOX: doxorubicin, ECG: electrocardiogram, ESR: electron spin resonance, ET: ventricular ejection time, iNOS: inducible nitric oxide synthase, IO: iron overload, i.p.: intra peritoneal, IR: ischemia/reperfusion, IVCT: isovolumic contraction time, IVRT: isovolumic relaxation time, IVS: inter ventricular septum, LVEDD: left ventricular end-diastolic diameter, LVEF: left ventricular ejection fraction, LVESD: left ventricular end-systolic diameter, LVMI: left ventricular mass indexed to body weight, LVPW: left ventricular posterior wall, mRNA: messenger ribonucleic acid, RONS: reactive oxygen and nitrogen species, RT-PCR: Reverse transcription polymerase chain reaction, SEM: standard error of the mean 


\section{Introduction}

Doxorubicin (DOX), a molecule belonging to the class of anthracycline antibiotics, is a broad-spectrum anticancer drug, particularly useful in the treatment of malignant lymphomas, acute leukemia, sarcomas and solid tumors such as breast, lung and ovary cancers [1]. However, despite good therapeutic results, the clinical use of DOX in chemotherapy is limited by the development of acute, sub-acute, and chronic cardiotoxicity [2, 3] leading to dosedependent congestive heart failure, which may occur several years after treatment cessation [4], and may affect up to $20 \%$ of cases [5, 6].

Several putative molecular mechanisms have been proposed to explain the cardiotoxicity of anthracyclines, but while the exact mechanism is still a matter of debate, it seems to be distinct from its anti-tumor activity since cardiomyocytes are minimally replicating cells [7]. Oxidative stress is believed to be an important pathway in the cardiac side-effects of anthracycline therapy [8-11] and related to the production of reactive oxygen and nitrogen species (RONS) during the intracellular metabolism of the quinone [12]. Additionally, DOX forms stable complexes with ferric iron [13], and the iron in the complex undergoes reduction to ferrous iron, resulting in the generation of a semiquinone free radical of DOX [14]. The semiquinone then reacts with oxygen to form superoxide anion radical $\left(\mathrm{O}_{2}{ }^{-\bullet}\right)$ that, in the presence of iron, is converted into hydroxyl radical through the Haber-Weiss reaction or forms peroxynitrite $\left(\mathrm{ONOO}^{-}\right)$in the presence of nitric oxide $\left({ }^{\circ} \mathrm{NO}\right)$ [15]. In turn, these potent RONS induce lipid peroxidation and DNA damage $[13,16]$, promoting the death of cardiac cells by apoptosis or necrosis. Moreover, DOX-mediated RONS production may lead to iron accumulation in ferritin, and the DOX-iron complex impairs iron regulatory protein (IRP) DNA-binding activity, leading to deregulation of iron homeostasis in cells. This process may lead to additional deleterious effects because iron is essential in several metabolic processes $[17,18]$. 
Although the involvement of iron in anthracycline-induced cardiotoxicity is suggested by studies in which iron chelators were shown to be cardioprotective $[19,20]$, some clinical trials led to disappointing results $[21,22]$. In experimental models, iron loading was found to potentiate anthracycline cardiotoxicity in cardiomyocytes [23, 24] and in vivo [25] as well as in hemochromatosis gene $\mathrm{Hfe}-/$ mice [26]. However, the pharmacological interaction between iron and anthracyclines still remains controversial and some authors found that DOX may paradoxically protect cardiomyocytes against iron-mediated cardiotoxicity [27], and that cardiomyocytes display a dose-dependent biphasic response to iron overload [28].

The aim of our study was first to investigate in vitro the ability of dextran-iron to modify the DOX-induced deterioration of cell viability in cultured cancer cells (EMT-6) and in cardiomyocytes (H9c2). Secondly, we sought to investigate in vivo in mice, the impact of chronic iron tissue loading on DOX-induced nitro-oxidative stress and cardiotoxicity. We evaluated iron status, nitro-oxidative stress levels and cardiac functional alterations. The major finding of our study is that, paradoxically, iron loading did not potentiate DOX cardiotoxicity, in either cell cultures or mice, raising once again the debate concerning the detrimental role of iron in DOX-induced cardiotoxicity. 


\section{Material and methods}

\subsection{Cell culture and treatments}

The H9c2 embryonic rat heart-derived and the EMT-6 mouse mammary carcinoma cell lines were obtained from American Type Culture Collection (ATCC, Manassas, VA). All cell lines were grown in Dulbecco's Modified Eagle's Medium (DMEM) supplemented with 10\% fetal bovine serum (FBS), $4 \mathrm{mM}$ L-glutamine, $100 \mathrm{U} / \mathrm{mL}$ penicillin, $100 \mathrm{U} / \mathrm{mL}$ streptomycin and $250 \mathrm{ng} / \mathrm{mL}$ amphotericin $\mathrm{B}$ in humidified air $\left(5 \% \mathrm{CO}_{2}\right)$ at $37^{\circ} \mathrm{C}$.

Cell viability was measured by COHIRO Biotechnology (Faculty of Medicine, Dijon, France) with XTT assay, based on the ability of metabolically active cells to reduce tetrazolium salt XTT (2,3-Bis-(2-methoxy-4-nitro-5-sulfophenyl]-2H-tetrazolium-5-carboxyanilide inner salt) to orange colored compounds of aqueous-soluble formazan crystals using mitochondrial dehydrogenases. Briefly, when the cultures reached $70-80 \%$ of confluence, cells were suspended in $0.05 \%(\mathrm{w} / \mathrm{v})$ trypsin / $0.53 \mathrm{mM}$ EDTA and plated at a density of 5,000 cells/well in 96-well plates in medium containing 5\% FBS and 2 mM L-glutamine. After 24 hours, Iron Dextran (Ferristat $\left.{ }^{\circledR}\right)$ was added to achieve final concentrations of 125, 250, 500 and 1,000 $\mu \mathrm{g} / \mathrm{mL}$ with or without $1 \mu \mathrm{M}$ Doxorubicin (Adriblastin ${ }^{\circledR}$ ) for 24 hours of treatment. Then, the medium was removed and replaced with fresh medium without FBS and L-glutamine containing $0.15 \mathrm{mg} / \mathrm{mL}$ XTT solution, and the cells were further cultured in the $\mathrm{CO}_{2}$ incubator at $37^{\circ} \mathrm{C}$ for 4 hours. The amount of formazan produced was detected by measuring absorbance at $499 \mathrm{~nm}$ and a reference wavelength was used at $660 \mathrm{~nm}$ on a microplate reader Infinite M200 Pro (TECAN, Lyon, France). Cell viability was expressed as a percentage of control, which was taken as $100 \%$. In all experiments quadruplicate wells were run and repeated at least twice with different cell preparations. 


\subsection{Animals and treatments}

Male C57Bl/6 mice (Charles River, L'Arbresle, France) aged 10 weeks were used. All animals received humane care and study protocols complied with the institution's guidelines. The investigation complied with Directive 2010/63/EU of the European Parliament and with the Guide for the Care and Use of Laboratory Animals published by the US National Institutes of Health (NIH Publication No. 85-23, revised 1996) and was approved by the local ethics committee (Comité d'Ethique de 1'Expérimentation Animale, Université de Bourgogne, Dijon, France, protocol agreement number: 3211). Throughout the procedure, care was taken to avoid suffering and to ensure animal welfare, for instance, through improving the environment in cages. During the protocol, no animals became moribund and needed to be killed early or died from the treatment.

The experimental protocol is described in Figure 1. In the first set of experiments aiming to evaluate the early effects of iron loading, at D0, 14 male mice underwent transthoracic echocardiography under isoflurane anesthesia (3-4\% for induction, then $1.5 \%$ throughout the procedure). Two study groups of seven mice each were created; one group received a daily intra-peritoneal (i.p.) injection of dextran/iron (IRON, $15 \mathrm{mg} / \mathrm{kg}$ ) and the other saline solution (CONT, $1 \mathrm{~mL} / \mathrm{kg}$ ) for 20 days, from D1 to D20. At D21, mice underwent echocardiography under isoflurane anaesthesia and were then killed (pentobarbital, $80 \mathrm{mg} / \mathrm{kg}$, i.p.) in order to collect blood and tissues.

In the second set of experiments aiming to evaluate the effects of iron loading on doxorubicin-induced cardiotoxicity, 32 male mice had echocardiography at D0 then, for 20 days (D1 to D20), they received a daily i.p. injection of dextran/iron or saline solution, followed or not at D21, by a single i.p. injection of doxorubicin (DOX, $6 \mathrm{mg} / \mathrm{kg}$ ). Four groups were then constituted, a control group (CONT, $\mathrm{n}=8$ ), iron loading alone (IRON, $\mathrm{n}=8$ ), doxorubicin alone (DOX, $n=8$ ) or the combination of iron and doxorubicin (IRON+DOX). At 
D30, all of the mice underwent echocardiography and were then killed in order to collect blood and tissues.

\subsection{Transthoracic echocardiographic imaging}

Transthoracic echocardiography using the Vevo770 ${ }^{\mathrm{TM}}$ imaging system (VisualSonics Inc., Toronto, Canada), equipped with a $30 \mathrm{MHz}$ probe was performed at D0, and D21 and D30 just before the mice were killed. Briefly, the mice were anesthetized with isoflurane. The body temperature of the mice was monitored using a rectal probe, and an infrared heating lamp was used to maintain body temperature at $37 \pm 0.5^{\circ} \mathrm{C}$ throughout the procedure. An electrocardiogram (ECG) signal was also monitored through electrode pads on the heated platform. Chest hair was removed using a chemical depilator to minimize ultrasound attenuation. The ultrasound probe (RMV-707B) was placed on the chest of the mice using warm ultrasound gel as a coupling medium.

Two-dimensional images were recorded in the parasternal long- and short-axis views to guide M-mode recordings obtained at the mid-ventricular level, with 3 to 5 measurements for each view in order to make an average. Wall thicknesses of the inter-ventricular septum (IVS) and left ventricular posterior wall (LVPW), as well as the LV diastolic and systolic internal dimensions (LVEDD and LVESD, respectively) were measured, and the average values were reported. LV systolic function was computed from the M-mode measurements according to the recommendations of the American Society of Echocardiography Committee. Left ventricular mass indexed to body weight (LVMI) was calculated using the formula:

Echo LV mass $=\left(V S T_{d}+L V I D_{d}+L V P W_{d}\right)^{3}-\left(L V I D_{d}\right)^{3} /$ body weight $(g)$

Pulsed Doppler studies of LV diastolic function were performed in the apical 4-chamber view with the Doppler cursor oriented parallel to the long-axis plane of the left ventricle. The sample volume was placed just below the level of the mitral valve and adjusted to render the 
highest early diastolic flow velocity peak of the transmitral Doppler flow signal. There was often a need for angle correction which was always less than 20 degrees. The early and late diastolic peak velocity $(\mathrm{E}, \mathrm{A})$ and their ratio $(\mathrm{E} / \mathrm{A})$ were derived from the transmitral Doppler waveform. Left ventricular systolic intervals of the isovolumic contract time (IVCT), the ventricular ejection time (ET) and diastolic intervals of the isovolumic relaxation time (IVRT) were also derived from the transmitral Doppler waveform. The myocardial performance index (Tei index) was calculated using the formula:

Tei index $=(I V C T+I V R T) / E T$

\subsection{Blood sampling and tissue processing}

At D21 for 14 mice, and D30 for 32 mice, after the echocardiography, the animals were anesthetized with sodium pentobarbital ( $80 \mathrm{mg} / \mathrm{kg}$, i.p.) until total loss of nociceptive reflexes (verified by paw pinching), and heparin was injected (500 IU/kg, i.p.). Blood was collected from the heart, and immediately centrifuged at $4^{\circ} \mathrm{C}$ in order to separate the plasma. The heart, liver, epididymal fat and kidneys were quickly harvested and immediately frozen in liquid nitrogen. Samples were then stored at $-80^{\circ} \mathrm{C}$ until subsequent measurements.

\subsection{Measurement of iron content}

Iron content was measured in non-hemolysed plasma, the myocardium, fat and liver from all animals using atomic absorption spectroscopy in the University facility (Wellience, Analytical Chemistry Pole, Faculty of Pharmacy, Dijon, France). Plasma and tissues were mineralized in a mixture of concentrated acids. Total iron content was determined using atomic absorption spectrometry in a graphite furnace. Total iron was established using the ContrAA 700 (Analytik Jena, Germany), a high-resolution continuous-source atomic absorption spectrometer, at the wavelength of $248.3270 \mathrm{~nm}$. 


\subsection{Oxidative stress measurements}

RONS in the heart were measured using electron spin resonance (ESR) spectroscopy [29]: freshly-harvested hearts were perfused with ice-cold saline solution to remove residual blood. Myocardial biopsies of $2.5 \mathrm{~mm}$ diameter were cut, rinsed, weighed and placed in a 24-well tissue culture plate containing $200 \mu \mathrm{L}$ of ESR-specific pH 7.4 Krebs-HEPES buffer, containing (in mM) Na-HEPES 20; $\mathrm{NaCl}, 99 ; \mathrm{NaHCO}_{3}, 25 ; \mathrm{KCl}, 4.69 ; \mathrm{MgSO}_{4}, 1.2 ; \mathrm{KH}_{2} \mathrm{PO}_{4}$, 1.03; $\mathrm{CaCl}_{2}, 2.5$; glucose, 5.5; to which deferroxamine $(25 \mu \mathrm{M})$ and diethyl-dithiocarbamate $(5 \mu \mathrm{M})$ were added to remove traces of contaminant metal ions. The spin probe 1-hydroxy-3methoxy-carbonyl-2,2,5,5- tetramethyl pyrrolidine $(\mathrm{CMH})$ was added in order to reach a final concentration of $100 \mu \mathrm{M}$, then the tissue was incubated for 15 minutes at $37^{\circ} \mathrm{C}$, in a $5 \% \mathrm{CO}_{2}$ atmosphere, in the presence of CMH. In the presence of RONS, the ESR-silent CMH hydroxylamine is oxidized into $\mathrm{CP}^{\bullet}$ nitroxide radical with a characteristic 3-line signal. The incubation medium and tissue were then collected and immediately frozen in liquid nitrogen in ESR-compatible polyethylene tubes. The frozen tissue and medium were analyzed at $100 \mathrm{~K}$ in a Bruker X-band EMX spectrometer (Bruker, Wissembourg, France) using an HS cavity, with the following recording parameters: amplitude modulation 5 gauss, frequency modulation $100 \mathrm{kHz}$, gain $2.10^{+5}$, time constant $328 \mathrm{~ms}$, conversion time $40.96 \mathrm{~ms}$, microwave frequency $9.37 \mathrm{GHz}$, field sweep $100 \mathrm{G}$, attenuation $10 \mathrm{~dB}$.

The height of the central anisotropic peak of the $\mathrm{CP}^{\bullet}$ signal was measured (in arbitrary units, $\mathrm{AU})$ and results were expressed in $\mathrm{AU} / \mathrm{mg}$ of fresh tissue. 


\subsection{Myocardial gene expression}

Total RNA was extracted from heart samples by Quiazol reagent (Invitrogen Life Technologies, Saint-Aubin, France). The quality and concentration were checked using Agilent technology.

mRNA $(1 \mu \mathrm{g})$ was reverse transcribed with MMLV reverse transcriptase (Invitrogen, id.) using random hexamers (Invitrogen, id.) according to the manufacturer's instructions. Realtime quantitative polymerase chain reaction (RT-PCR) was performed with $2 \mu \mathrm{l}$ of cDNA using the SYBR-Green PCR Master-Mix (Applied Biosystems) and both sense and antisense primers $(5 \mu \mathrm{M})$ in a final volume of $20 \mu \mathrm{L}$, in an 7500-Standard-Real-Time PCR system (Applied Biosystems). Cardiac mRNA levels of beta-myosin heavy chain ( $\beta$ MHC), atrial natriuretic peptide (ANP), brain natriuretic peptide (BNP), catalase, manganese- and extracellular superoxide dismutase (Mn-SOD and Ec-SOD), $\alpha$-B-crystallin and heat shock proteins (hsp) 20, 27, 70 and 90B were analyzed. Target gene expression was normalized against the housekeeping hypoxanthine-guanine phosphoribosyltransferase (HPRT) gene expression. The abundance of each target mRNA was normalized to that of HPRT mRNA. The primers used for the amplification of mouse genes are provided in Table 1.

\subsection{Statistical Methods}

Continuous data were expressed as mean (standard deviation) or median $\left(25^{\text {th }}\right.$ percentile $-75^{\text {th }}$ percentile) and dichotomous data as numbers (percentages). For continuous variables, the normality of distribution was tested by the Shapiro-Wilk test. One-way ANOVA was used to compare both groups at day 21 .

At day 30, because of the presence of two factors in the treatment groups, all other continuous data were compared using 2-way ANOVA. This allowed analysis of the iron and doxorubicin 
effect, and the potential interaction of these two factors. Post-hoc analyses were done with Tukey's test if appropriate.

Analyses were done using Sigma Plot 12.0 (Systat software, USA). 


\section{Results}

\subsection{Effect on cell viability of DOX, in combination with dextran-iron, in cultured cells}

In a series of preliminary experiments, the effect of DOX on cell viability was tested at different concentrations in cultures of cancerous cells (EMT-6) or cardiomyocytes (H9c2). The concentration of $1 \mu \mathrm{M}$ was chosen because it was able to impair the viability of these cells in our experimental conditions by about $25 \%$. Increasing concentrations of iron-dextran, from 125 to $1,000 \mu \mathrm{g} / \mathrm{mL}$ did not change cell viability in either EMT-6 or H9c2 cells in the absence of DOX (figures $2 \mathrm{~A}$ and B). The incubation of cells with $1 \mu \mathrm{M}$ of DOX for 20 hours reduced viability to $72.99 \pm 2.08 \%$ in EMT-6 (figure $2 \mathrm{C}$ ) and to $69.77 \pm 5.77 \%$ in $\mathrm{H} 9 \mathrm{c} 2$ (figure 2D). However, pre-treatment of the cells during $4 \mathrm{~h}$ before DOX with increasing concentrations of dextran-iron $(125-1,000 \mu \mathrm{g} / \mathrm{mL})$ did not modify DOX cytotoxicity, showing no intensification of the cytotoxic effects of DOX by iron pretreatment. We therefore aimed to transpose this results obtained in vitro to an in vivo model.

\subsection{Iron levels in plasma and tissue}

Iron levels were evaluated in the plasma and in several tissues at D21 and D30 (Figure 3), in order to validate the IO model in mice, and to observe possible relationships between DOX treatment and iron tissue status. In the plasma, 20 days of daily dextran-iron injections (15 $\mathrm{mg} / \mathrm{kg}$ ) led to a major increase in plasma iron concentration at D21 (Figure 3A, $2.23 \pm 0.38$ $\mathrm{mg} / \mathrm{L}$, vs. $9.30 \pm 1.44 \mathrm{mg} / \mathrm{L}, \mathrm{p}<0.001$ ) which returned to that in control mice at $\mathrm{D} 30$, ten days after the last dose of iron. Interestingly, plasma iron level in the IRON-DOX group was significantly higher than that in the IRON group ( $\mathrm{p}=0.013)$. In myocardial tissue, 20 days of daily injections of dextran-iron did not change myocardial iron levels; however, at D30, myocardial iron content in the IRON group had more than doubled while the levels in both groups with the single DOX injection (with and without iron) had not increased significantly. 
Moreover, a significant interplay between iron and DOX was observed $(\mathrm{p}=0.049)$, in which treatment with DOX induced a decrease in myocardial iron content in IO mice. In the liver, pretreatment with iron increased hepatic iron content by more than 10 times $(p=0.038)$ at $D 20$ and 6 times at D30 $(\mathrm{p}<0.001)$, while the injection of DOX in the context of IO led to a smaller increase in liver iron content $(\mathrm{p}=0.025)$. In epididymal fat, iron loading with dextran-iron led to dramatic increases in iron content $(\times 33$ at D20, $p<0.001)$, which remained extremely high at D30 ( $\mathrm{p}<0.001)$. The administration of DOX did not modify fat iron content, but DOX decreased iron content in IO mice at D30 $(\mathrm{p}=0.025)$. Overall, the results confirmed the presence of IO in all investigated tissues, though the kinetics in the heart were distinctly different from those in the liver and fat, and showed an interplay between DOX and iron in all tissues; DOX tended to decrease iron content and/or to accelerate the elimination of iron from these tissues. We therefore investigated the myocardial repercussions of IO and DOX on myocardial function, oxidative stress and gene expression.

\subsection{Myocardial dysfunction}

\section{Measurement of left ventricular function by echocardiography}

Because of physiological variations in LV parameters in mice, each mouse was compared with itself at baseline and D21 and D30 (Table 2). The percentage of variation compared with baseline values was calculated: namely the change in left ventricular ejection fraction $(\triangle \mathrm{LVEF})$ and in left ventricular mass ( $\triangle \mathrm{LVMI})$ (figure $4 \mathrm{~A}$ and $4 \mathrm{~B}$, respectively).

Twenty days of daily injections of dextran-iron $(15 \mathrm{mg} / \mathrm{kg})$ did not modify LVEF at D21. At D30, there was a significant decrease in systolic function assessed by a fall in LVEF in DOX $(44 \% \pm 7$ vs. $62 \% \pm 5, \mathrm{p}<0.001)$ and IRON-DOX $(51 \% \pm 5$ vs. $63 \% \pm 9, \mathrm{p}=0.012)$ groups as compared with their baseline values. A significant increase in LVMI was observed in the IRON group at D21 (figure 4B, p=0.031) and D30 ( $\mathrm{p}=0.013)$, compared with baseline values 
and values of the other groups; moreover, a significant interplay between iron and doxorubicin was observed, in which DOX decreased LVMI in IO mice $(\mathrm{p}=0.004)$.

Concerning left ventricular diameters, there was a significant increase in LVEDD in the DOX group compared with baseline $(4.06 \pm 0.25 \mathrm{~mm}$ vs. $3.67 \pm 0.35 \mathrm{~mm}, \mathrm{p}=0.007)$, but not in the IRON-DOX group. There was no significant difference among groups for all of the diastolic parameters $(\Delta \mathrm{E} / \mathrm{A}, \Delta \mathrm{IVRT}, \Delta \mathrm{Tei}$ index $)$.

Collectively, these results confirm that IO alone did not impair left ventricular function but induced left ventricular hypertrophy, and that IO did not exacerbate DOX-induced impairment of LVEF. We therefore aimed to link these functional results to cellular markers of hypertrophy, heart failure and oxidative stress.

Cellular markers of hypertrophy and heart failure: myocardial mRNA expression of ANP, $B N P$ and $\beta M H C$

There were significant differences among groups regarding myocardial expression of ANP, $\mathrm{BNP}$, and $\beta \mathrm{MHC}$ assessed by qRT-PCR (figure 5). At D21, pretreatment with iron led to a significant increase in the expression of BNP $(\mathrm{p}<0.001)$. At D30, the expressions of ANP $(16.50 \pm 5.71$ vs. $7.35 \pm 3.62, \mathrm{p}=0.004, \mathrm{AU})$ and $\beta \mathrm{MHC}(0.77 \pm 0.18$ vs. $0.35 \pm 0.14, \mathrm{p}=0.014$ AU) were increased by DOX. Additionally, IO in mice treated with DOX further increased the expression of BNP $(27.15 \pm 6.70$ vs. $18 \pm 4.99, \mathrm{p}=0.025, \mathrm{AU})$ and $\beta \mathrm{MHC}(1.09 \pm 0.26$ vs. $0.77 \pm 0.18, \mathrm{p}=0.048, \mathrm{AU})$.

\subsection{Oxidative stress measurements}

\section{Measurement of RONS in the heart using ESR spectroscopy}

Due to the fact that ESR was measured in three different sets of experiments, separated by several months, the data had to be homogenized, and signals were therefore compared with 
those obtained in control hearts (CONT) for which the signal intensity was considered as $100 \%$ (figure 6A). At D21, CP radical intensity was increased in hearts from IRON mice $(\mathrm{p}=0.045)$. Comparing all groups at $\mathrm{D} 30$, we found a significantly higher $\mathrm{CP}^{\bullet}$ signal intensity in the IRON group than in the CONT group $(\mathrm{p}=0.036)$, and in the IRON-DOX group than in the DOX group $(\mathrm{p}=0.041)$.

\section{Myocardial expression of anti-oxidant enzyme}

Concerning the mRNA expression of antioxidant enzymes, treatment with iron induced no significant modifications at D21. At D30, the expression of catalase and Ec-SOD was greater in the IRON group $(\mathrm{p}=0.001)$ than in the CONT group. Curiously, the injection of DOX in mice pretreated with iron limited the increase in the expression of catalase $(\mathrm{p}=0.007)$ and EcSOD $(\mathrm{p}=0.005)$ as compared with that in the IRON group. No modifications in Mn-SOD expression were induced by the different treatments at any observation time.

These results led us to the conclusion that IO induced an increase in the production of reactive oxygen/nitrogen species in the myocardial tissue, which was then compensated for by the upregulated expression of antioxidant enzymes. This mechanism may counterbalance the deleterious redox effects induced by DOX. We therefore sought to investigate other potentially protective mechanisms such as heat shock protein (hsp) expression.

\subsection{Expression of heat shock proteins}

The expression of several hsp was measured at D21 in control and IO hearts. While the mRNA expression in the following hsp genes, namely hsp70, $\alpha \mathrm{B}$-cristallin, hsp90B and hsp27, was not modified by treatment with iron/dextran (Table 3), that of the small hsp20 was statistically increased at D21 in hearts of mice pretreated with $15 \mathrm{mg} / \mathrm{kg}$ iron-dextran. 


\section{Discussion}

The first aim of our study was to evaluate the effects of the combination of iron and DOX on cell viability in two cell lines: cancerous EMT-6 and H9c2 cardiomyocytes. While $1 \mu \mathrm{M}$ of DOX induced a significant reduction in EMT-6 or H9c2 cell viability, dextran-iron (125-1000 $\mu \mathrm{g} / \mathrm{mL}$ ) alone did not modify viability. When both cell lines were pre-incubated with increasing concentrations of dextran-iron, the activity of DOX against cell viability was not modified. In neonatal rat cardiomyocytes, Link et al. $[24,30]$ showed that $20 \mu \mathrm{g} / \mathrm{mL}$ of ferric ammonium citrate (FAC) could induce lactate dehydrogenase release and impair mitochondrial respiratory chain activity, while the adjunction of $1.7 \mu \mathrm{M}$ of DOX increased cytotoxicity. More recently, in H9c2 cardiomyocytes and murine embryonic fibroblasts, FAC decreased the viability of cells incubated in the presence of $5 \mu \mathrm{M}$ of DOX [31]. However, Corna et al. [32] were able to demonstrate that DOX, in concentrations ranging from 5 to 10 $\mu \mathrm{M}$, paradoxically protected $\mathrm{H} 9 \mathrm{c} 2$ cardiomyocytes against the toxicity of ferric ammonium citrate. Our study, like theirs, showed that iron neither systematically reinforces the toxic effects of DOX on cardiomyocytes, nor impairs the ability of DOX to alter cell viability in cancerous cell lines. We therefore aimed to determine whether these results obtained in vitro were replicated in an in vivo model.

We therefore aimed to validate the IO model, and to determine whether prior iron loading could aggravate cardiovascular and oxidative lesions induced by DOX treatment in mice.

Indeed, after 3 weeks of daily injections of iron-dextran, leading to a total cumulative dose of $315 \mathrm{mg} / \mathrm{kg}$, the concentration of iron in the plasma, liver and fat increased dramatically, while, paradoxically, it did not in the heart. At D30, ten days after stopping the iron injections, plasma iron levels decreased to normal values. The fall in concentrations in the liver and fat 
was more pronounced in mice also treated with DOX. At this time, iron levels in the myocardium of mice pretreated with iron had more than doubled, while no changes were observable earlier. We can only speculate on the reasons for this difference, but our results are in accordance with those obtained in rats [25] and mice [33] and confirm the fact that early on iron mainly accumulates in the liver and fat, while accumulation in other tissues, including the heart, occurs later and at a lower level, and that accumulation may be susceptible to pharmacological interactions with DOX. In rats, Panjrath et al. found no significant effect of doxorubicin on myocardial iron content 2 to 3 weeks after treatment (intravenous $6 \mathrm{mg} / \mathrm{kg}$ single dose of doxorubicin) [25]. However, Miranda et al. found a significant increase in iron content in the plasma and in the liver, spleen and heart of wild-type female mice 4 days after a single $20 \mathrm{mg} / \mathrm{kg}$ dose of doxorubicin [26]. These conflicting results could be partially explained by the three-fold higher dose of doxorubicin used in these previous studies, which could have led to erythrocyte damage [13] and thus induce the release of iron from hemoglobin, as suggested by the large amount of iron in the spleen and macrophages.

Concerning heart function, we observed an increase in LVMI, a marker of hypertrophic changes, in the IRON group at D21 and D30. The pathological impact of iron overload on myocardial function is complex. Moon et al. established a mouse model of iron overload (IO) [33], in which echocardiographic evaluations revealed an increase in wall thickness without alterations in LV systolic function. In the present study, the large increase in echocardiographic LVMI was associated with the up-regulation of BNP (D21) and $\beta$ MHC (D30) mRNA cardiac levels, both of which are considered markers of myocardial remodeling and hypertrophy [34]. Interestingly, our model of IO in mice did not induce heart failure, as proved by the preservation of LV function. In fact, Yang et al showed that short durations of IO induced eccentric cardiac hypertrophy and increased cardiac output in Mongolian gerbils, 
while longer durations of IO led to concentric cardiac hypertrophy and cardiac output impairment [35].

This accumulation of iron could trigger an increase in myocardial oxidative stress. In fact, ESR spectroscopy revealed a significantly higher $\mathrm{CP}^{\bullet}$ signal intensity in the IRON group than in the CONT group. As an adaptive response, the myocardial gene expression of catalase and ecSOD were significantly increased in the IRON group. Bartfay et al. observed that a chronic iron overload in mice resulted in free radical-mediated alterations of cardiac function, as measured by excess concentrations of cytotoxic aldehyde-derived peroxidation products [36]. Moreover, Al-Rousan et al. described a 100\% increase in superoxide abundance and a 114\% increase in protein oxidation in the myocardium after 10 weeks of massive iron overload [37]. Excess "labile iron"' is potentially detrimental to cells because of its propensity to participate in oxidation-reduction reactions that generate harmful free radicals [38]. However, in our experimental conditions, the increase in myocardial oxidative stress was accompanied by the up-regulation of antioxidant gene expression, which may have played a counterbalancing role in this situation.

Concerning the effects of a single intra-peritoneal dose of $6 \mathrm{mg} / \mathrm{kg}$ of DOX in mice, at D30, there was a fall in LVEF and a significant increase in LVEDD in the DOX group as compared to baseline values, but no mice died following the treatment. Indeed, LV systolic function impairment is a well-known side-effect of doxorubicin treatment in humans [6]. In mice, Walker et al found similar results 10 days after a single dose of $20 \mathrm{mg} / \mathrm{kg}$ of doxorubicin [39]. Interestingly, the dose of DOX that we used in our study, which did not lead to any deaths, may be regarded as mild as compared to the usual doses used to induce acute cardiac toxicity in rodents. However, this single injection was able to induce alterations in cardiac contractility in the DOX group and to up-regulate the mRNA expression of ANP and $\beta \mathrm{MHC}$ in heart tissue. Regarding natriuretic peptides, our results are in accordance with those of 
Huelsenbeck et al.: 2 days after a single dose of $10 \mathrm{mg} / \mathrm{kg}$ in mice, doxorubicin caused a large increase in the amount of ANP, but not BNP mRNA levels [40]. In a previous study carried out in our laboratory, we found that chronic treatment with doxorubicin in rats was able to induce the mRNA expression of $\beta \mathrm{MHC}$ in ventricular tissue [9]. Indeed, pathological cardiac dysfunction has been associated with the up-regulation of fetal genes such as ANP [41] and $\beta \mathrm{MHC}$. ANP is a natriuretic peptide secreted by atrial myocytes under normal conditions. In a failing heart, ventricular myocytes also secrete ANP [42]. The expression of the $\alpha$ and $\beta$ isoforms of MHC genes is developmentally regulated in the myocardium [43]. One consistent molecular marker of DOX-induced cardiac maladaptation is the up-regulation of $\beta \mathrm{MHC}$ with the corresponding down-regulation in $\alpha \mathrm{MHC}$. Therefore, a relationship exists between the decreased contractile performance and the relative increase in $\beta \mathrm{MHC}$ expression. Increased levels of cardiac ANP and $\beta$ MHC mRNA in the DOX group in our study, along with alterations in ventricular contractility, measured using echocardiography, are in accordance with this pathophysiological mechanism and can be linked to doxorubicin-induced cardiomyopathy.

Finally, we set out to determine whether prior IO could potentiate DOX cardiotoxicity. Unlike the DOX group, the IRON-DOX group did not develop significant left ventricular dilation compared with baseline values, and at D30, LVEF was not statistically different from that of the CONT group at the same time (table 2). Thus, the LV functional impairment observed in the IRON-DOX group was slightly reduced by prior IO when compared with the DOX group. The cardiac mRNA levels of heart injury were in accordance with this finding. In fact, unlike ANP levels in DOX mice, those in IRON-DOX mice and IRON mice were no higher than those in control mice: there was a statistically significant interaplay between iron and DOX that prevented the overexpression of myocardial ANP. However, myocardial levels of BNP 
and $\beta \mathrm{MHC}$ mRNA in the IRON-DOX group were higher than those in the DOX group, but not those in the IRON group. These data highlight the role of iron in myocardial remodeling and hypertrophy as previously discussed. Our findings contradict the conclusions of Panjrath et al., who found that oral IO in rats potentiated DOX cardiotoxicity, assessed by an increase in ex-vivo myocardial ${ }^{99 \mathrm{~m}} \mathrm{Tc}$ annexin-V uptake [25]. However, the present study cannot be compared to the Panjrath study because of marked differences in cardiac evaluation and the lack of direct markers of heart failure in the Panjrath study. Miranda et al found, in Hfe -/female mice undergoing chronic DOX treatment, a higher degree of mitochondrial damage in the heart than that in wild-type mice. However, no evaluation of cardiac function was performed in this study, even though the authors concluded that these mice showed increased sensitivity to the cardiotoxic effects of DOX using mortality rates [26]. However, given the very high doses of DOX delivered in the Miranda study (20 mg/kg), and the absence of direct proof of myocardial injury, this higher mortality rates could also be linked to systemic damage induced by DOX. Moreover, until now, the role of IO on DOX cardiotoxicity had never been assessed using in vivo functional measurements such as echocardiography.

Our findings can be linked to those of Corna et al., who reported a paradoxical benefit of anthracycline-derived reactive oxygen species, increased ferritin synthesis and resistance to iron-mediated damage [32]. However, in our study, DOX was given after the IO, and our results suggest that prior IO could have partially reduced sub-acute DOX-induced myocardial damage, in the same way that prior stress, like hyperthermia, [44] or endurance training [45] reduces myocardial damage. This is the reason why we investigated the possible induction of heat shock proteins (hsp), which have been extensively shown to exert protective effects against anthracycline cardiotoxicity [44, 46, 47]. We found that only hsp20 was induced by IO. This small hsp is transiently up-regulated in many tissues following stressful stimuli and has been shown to be highly protective against pathological cardiac processes [48], including 
DOX-induced cardiotoxicity [49]. Indeed, Metzler et al. observed that two weeks of iron pretreatment in mice was beneficial in the context of in vivo myocardial ischemia/ reperfusion injury [50]: troponin T levels, as a marker of myocardial damage, histological infarction area and damage score were significantly lower in iron-treated animals. In parallel, superoxide dismutase expression was increased in infarcted regions of iron-treated mice, whereas myocardial inducible nitric oxide synthase (iNOS) expression was significantly lower. Our ESR spectroscopy results are in accordance with these findings: we observed higher myocardial $\mathrm{CP}^{\bullet}$ signal intensity in the IRON-DOX group than in the DOX group, which is consistent with an increase in myocardial oxidative stress. Munoz et al., in an elegant in vitro study, proved that the effects of iron on cardiomyocytes could be visualized as a biphasic response: a low concentration of iron which stimulated iNOS activity and enhanced nitric oxide production, by promoting hypertrophy and enhancing survival mechanisms through RONS reduction, was beneficial to cardiomyocytes [34]. It has been reported that the stimulated synthesis of NO is involved in this protection. A complex relationship between iron homeostasis and NO metabolism has also been described [51].

\section{Study limitations}

The relatively small sample size is one of the limitations of the study: it was related to managing the large number of groups and the duration of treatment with daily intra-peritoneal injections of iron-dextran. The absence of a major increase in iron content in myocardial tissue after IO while other organs such as the liver and fat showed dramatic increases in iron content was an unexpected result, but was confirmed by a double analysis. It was therefore difficult to establish a direct interaction between DOX and catalytically active iron at high levels inside the myocardial tissue at the time of the DOX injection (D21). However, iron levels in the heart at D30 were high, showing that IO occurs relatively late in myocardial 
tissue. Finally, only one moderate dose of DOX $(6 \mathrm{mg} / \mathrm{kg})$ was used in our experimental conditions, and therefore we cannot speculate about the possible effects of IO in DOXinduced cardiotoxicity for higher acute or chronic doses of anthracyclines.

\section{Conclusion}

In our experimental conditions of moderate doxorubicin-induced cardiotoxicity in mice, IO did not result in a significant increase in cardiac impairment evaluated at both the functional and molecular levels. On the contrary, our results even suggest that prior chronic oxidative stress induced by IO could mitigate doxorubicin cardiotoxicity through a "preconditioning" phenomenon that has not yet been elucidated, but may involve the induction of the small hsp20. Additionally, in cardiomyocytes and cancerous cell lines, iron neither reinforces DOX toxicity nor impairs its ability to lessen cell proliferation. Therefore, these results suggest that the role of iron in anthracycline-induced cardiotoxicity may be more complicated than currently believed, and raise doubts about the commonly accepted concept of the iron-driven oxidative alterations involved in the cardiotoxic effects of DOX. 


\section{Acknowledgements:}

The authors thank Jean-Luc Beltramo (CSAAB, Faculty of Pharmacy, Dijon, France) for the measurement of iron by spectroscopic atomy, Stéphanie Delemasure (COHIRO, Faculty of Medicine, Dijon, France) for help in performing cell cultures and Françoise Bechet for technical assistance. The authors thank Mr. Philip Bastable for English revision of the manuscript. 


\section{References}

[1] Young RC, Ozols RF, Myers CE. The anthracycline antineoplastic drugs. N Engl J Med. 1981;305:139-53.

[2] Torti FM, Bristow MM, Lum BL, Carter SK, Howes AE, Aston DA, et al. Cardiotoxicity of epirubicin and doxorubicin: assessment by endomyocardial biopsy. Cancer research. 1986;46:3722-7.

[3] Horan PG, McMullin MF, McKeown PP. Anthracycline cardiotoxicity. Eur Heart J. 2006;27:1137-8.

[4] Steinherz LJ, Steinherz PG, Tan CT, Heller G, Murphy ML. Cardiac toxicity 4 to 20 years after completing anthracycline therapy. Jama. 1991;266:1672-7.

[5] Chatterjee K, Zhang J, Honbo N, Karliner JS. Doxorubicin cardiomyopathy. Cardiology. 2010;115:155-62.

[6] Singal PK, Iliskovic N. Doxorubicin-induced cardiomyopathy. N Engl J Med. 1998;339:900-5.

[7] Shi Y, Moon M, Dawood S, McManus B, Liu PP. Mechanisms and management of doxorubicin cardiotoxicity. Herz. 2011;36:296-305.

[8] Delemasure S, Sicard P, Lauzier B, Moreau D, Vergely C, Rochette L. Acute administration of epirubicin induces myocardial depression in isolated rat heart and production of radical species evaluated by electron spin resonance spectroscopy. J Cardiovasc Pharmacol. 2007;50:647-53.

[9] Richard C, Ghibu S, Delemasure-Chalumeau S, Guilland JC, Des Rosiers C, Zeller M, et al. Oxidative stress and myocardial gene alterations associated with Doxorubicin-induced cardiotoxicity in rats persist for 2 months after treatment cessation. J Pharmacol Exp Ther. 2011;339:807-14.

[10] Richard C, Lauzier B, Delemasure S, Talbot S, Ghibu S, Collin B, et al. Effects of angiotensin-1 converting enzyme inhibition on oxidative stress and bradykinin receptor expression during doxorubicin-induced cardiomyopathy in rats. J Cardiovasc Pharmacol. 2008;52:278-85.

[11] Ghibu S, Delemasure S, Richard C, Guilland JC, Martin L, Gambert S, et al. General oxidative stress during doxorubicin-induced cardiotoxicity in rats: absence of cardioprotection and low antioxidant efficiency of alpha-lipoic acid. Biochimie. 2012;94:932-9.

[12] Myers CE, McGuire WP, Liss RH, Ifrim I, Grotzinger K, Young RC. Adriamycin: the role of lipid peroxidation in cardiac toxicity and tumor response. Science. 1977;197:165-7.

[13] Myers CE, Gianni L, Simone CB, Klecker R, Greene R. Oxidative destruction of erythrocyte ghost membranes catalyzed by the doxorubicin-iron complex. Biochemistry. 1982;21:1707-12.

[14] Gutteridge JM. Lipid peroxidation and possible hydroxyl radical formation stimulated by the self-reduction of a doxorubicin-iron (III) complex. Biochem Pharmacol. 1984;33:1725-8.

[15] Malisza KL, Hasinoff BB. Production of hydroxyl radical by iron(III)-anthraquinone complexes through self-reduction and through reductive activation by the xanthine oxidase/hypoxanthine system. Arch Biochem Biophys. 1995;321:51-60.

[16] Muindi JR, Sinha BK, Gianni L, Myers CE. Hydroxyl radical production and DNA damage induced by anthracycline-iron complex. FEBS Lett. 1984;172:226-30.

[17] Xu X, Persson HL, Richardson DR. Molecular pharmacology of the interaction of anthracyclines with iron. Mol Pharmacol. 2005;68:261-71. 
[18] Ammar el SM, Said SA, Suddek GM, El-Damarawy SL. Amelioration of doxorubicininduced cardiotoxicity by deferiprone in rats. Canadian journal of physiology and pharmacology. 2011;89:269-76.

[19] Dorr RT. Cytoprotective agents for anthracyclines. Semin Oncol. 1996;23:23-34.

[20] Pouillart P. Evaluating the role of dexrazoxane as a cardioprotectant in cancer patients receiving anthracyclines. Cancer Treat Rev. 2004;30:643-50.

[21] Wouters KA, Kremer LC, Miller TL, Herman EH, Lipshultz SE. Protecting against anthracycline-induced myocardial damage: a review of the most promising strategies. $\mathrm{Br} \mathrm{J}$ Haematol. 2005;131:561-78.

[22] van Dalen EC, Caron HN, Dickinson HO, Kremer LC. Cardioprotective interventions for cancer patients receiving anthracyclines. Cochrane Database Syst Rev. 2008:CD003917.

[23] Hershko C, Link G, Tzahor M, Kaltwasser JP, Athias P, Grynberg A, et al. Anthracycline toxicity is potentiated by iron and inhibited by deferoxamine: studies in rat heart cells in culture. The Journal of laboratory and clinical medicine. 1993;122:245-51.

[24] Link G, Tirosh R, Pinson A, Hershko C. Role of iron in the potentiation of anthracycline cardiotoxicity: identification of heart cell mitochondria as a major site of iron-anthracycline interaction. The Journal of laboratory and clinical medicine. 1996;127:272-8.

[25] Panjrath GS, Patel V, Valdiviezo CI, Narula N, Narula J, Jain D. Potentiation of Doxorubicin cardiotoxicity by iron loading in a rodent model. $\mathrm{J}$ Am Coll Cardiol. 2007;49:2457-64.

[26] Miranda CJ, Makui H, Soares RJ, Bilodeau M, Mui J, Vali H, et al. Hfe deficiency increases susceptibility to cardiotoxicity and exacerbates changes in iron metabolism induced by doxorubicin. Blood. 2003;102:2574-80.

[27] Corna G, Santambrogio P, Minotti G, Cairo G. Doxorubicin Paradoxically Protects Cardiomyocytes against Iron-mediated Toxicity. Journal of Biological Chemistry. 2004;279:13738-45.

[28] Munoz JP, Chiong M, García L, Troncoso R, Toro B, Pedrozo Z, et al. Iron induces protection and necrosis in cultured cardiomyocytes: Role of reactive oxygen species and nitric oxide. Free Radical Biology and Medicine. 2010;48:526-34.

[29] Vergely C, Maupoil V, Clermont G, Bril A, Rochette L. Identification and quantification of free radicals during myocardial ischemia and reperfusion using electron paramagnetic resonance spectroscopy. Arch Biochem Biophys. 2003;420:209-16.

[30] Link G, Saada A, Pinson A, Konijn AM, Hershko C. Mitochondrial respiratory enzymes are a major target of iron toxicity in rat heart cells. The Journal of laboratory and clinical medicine. 1998;131:466-74.

[31] Xu X, Sutak R, Richardson DR. Iron chelation by clinically relevant anthracyclines: alteration in expression of iron-regulated genes and atypical changes in intracellular iron distribution and trafficking. Mol Pharmacol. 2008;73:833-44.

[32] Corna G, Santambrogio P, Minotti G, Cairo G. Doxorubicin paradoxically protects cardiomyocytes against iron-mediated toxicity: role of reactive oxygen species and ferritin. $\mathbf{J}$ Biol Chem. 2004;279:13738-45.

[33] Moon SN, Han JW, Hwang HS, Kim MJ, Lee SJ, Lee JY, et al. Establishment of secondary iron overloaded mouse model: evaluation of cardiac function and analysis according to iron concentration. Pediatr Cardiol. 2011;32:947-52.

[34] Munoz JP, Chiong M, Garcia L, Troncoso R, Toro B, Pedrozo Z, et al. Iron induces protection and necrosis in cultured cardiomyocytes: Role of reactive oxygen species and nitric oxide. Free Radic Biol Med. 2010;48:526-34.

[35] Yang T, Dong WQ, Kuryshev YA, Obejero-Paz C, Levy MN, Brittenham GM, et al. Bimodal cardiac dysfunction in an animal model of iron overload. The Journal of laboratory and clinical medicine. 2002;140:263-71. 
[36] Bartfay WJ, Dawood F, Wen WH, Lehotay DC, Hou D, Bartfay E, et al. Cardiac function and cytotoxic aldehyde production in a murine model of chronic iron-overload. Cardiovasc Res. 1999;43:892-900.

[37] Al-Rousan RM, Paturi S, Laurino JP, Kakarla SK, Gutta AK, Walker EM, et al. Deferasirox removes cardiac iron and attenuates oxidative stress in the iron-overloaded gerbil. Am J Hematol. 2009;84:565-70.

[38] Deb S, Johnson EE, Robalinho-Teixeira RL, Wessling-Resnick M. Modulation of intracellular iron levels by oxidative stress implicates a novel role for iron in signal transduction. Biometals : an international journal on the role of metal ions in biology, biochemistry, and medicine. 2009;22:855-62.

[39] Walker JR, Sharma A, Lytwyn M, Bohonis S, Thliveris J, Singal PK, et al. The cardioprotective role of probucol against anthracycline and trastuzumab-mediated cardiotoxicity. J Am Soc Echocardiogr. 2011;24:699-705.

[40] Huelsenbeck J, Henninger C, Schad A, Lackner KJ, Kaina B, Fritz G. Inhibition of Rac1 signaling by lovastatin protects against anthracycline-induced cardiac toxicity. Cell Death Dis. 2011;2:e190.

[41] Hystad ME, Geiran OR, Attramadal H, Spurkland A, Vege A, Simonsen S, et al. Regional cardiac expression and concentration of natriuretic peptides in patients with severe chronic heart failure. Acta Physiol Scand. 2001;171:395-403.

[42] van den Bosch BJ, Lindsey PJ, van den Burg CM, van der Vlies SA, Lips DJ, van der Vusse GJ, et al. Early and transient gene expression changes in pressure overload-induced cardiac hypertrophy in mice. Genomics. 2006;88:480-8.

[43] Lompre AM, Mercadier JJ, Schwartz K. Changes in gene expression during cardiac growth. Int Rev Cytol. 1991;124:137-86.

[44] Ito H, Shimojo T, Fujisaki H, Tamamori M, Ishiyama S, Adachi S, et al. Thermal preconditioning protects rat cardiac muscle cells from doxorubicin-induced apoptosis. Life Sci. 1999;64:755-61.

[45] Ascensao A, Magalhaes J, Soares J, Ferreira R, Neuparth M, Marques F, et al. Endurance training attenuates doxorubicin-induced cardiac oxidative damage in mice. International journal of cardiology. 2005;100:451-60.

[46] Krishnamurthy K, Kanagasabai R, Druhan LJ, Ilangovan G. Heat shock protein 25enriched plasma transfusion preconditions the heart against doxorubicin-induced dilated cardiomyopathy in mice. J Pharmacol Exp Ther. 2012;341:829-39.

[47] Turakhia S, Venkatakrishnan CD, Dunsmore K, Wong H, Kuppusamy P, Zweier JL, et al. Doxorubicin-induced cardiotoxicity: direct correlation of cardiac fibroblast and H9c2 cell survival and aconitase activity with heat shock protein 27. Am J Physiol Heart Circ Physiol. 2007;293:H3111-21.

[48] Edwards HV, Cameron RT, Baillie GS. The emerging role of HSP20 as a multifunctional protective agent. Cellular signalling. 2011;23:1447-54.

[49] Fan GC, Zhou X, Wang X, Song G, Qian J, Nicolaou P, et al. Heat shock protein 20 interacting with phosphorylated Akt reduces doxorubicin-triggered oxidative stress and cardiotoxicity. Circ Res. 2008;103:1270-9.

[50] Metzler B, Jehle J, Theurl I, Ludwiczek S, Obrist P, Pachinger O, et al. Short term protective effects of iron in a murine model of ischemia/reperfusion. Biometals : an international journal on the role of metal ions in biology, biochemistry, and medicine. 2007;20:205-15.

[51] Galleano M, Simontacchi M, Puntarulo S. Nitric oxide and iron: effect of iron overload on nitric oxide production in endotoxemia. Molecular aspects of medicine. 2004;25:141-54. 


\section{Figure Legends:}

\section{Figure 1: Experimental design and study groups.}

Experiment 1: at D0, 14 male mice underwent transthoracic echocardiography. From D1 to D20 mice received a daily i.p. injection of dextran/iron (IRON, $15 \mathrm{mg} / \mathrm{kg}$ ) or saline (CONT, 1 $\mathrm{mL} / \mathrm{kg}$ ). At D21, all mice underwent echocardiography.

Experiment 2: at D0, 32 male mice underwent transthoracic echocardiography. From D1 to D20 mice received a daily i.p. injection of dextran/iron or saline solution, followed or not at D21, by a single i.p. injection of doxorubicin (DOX, $6 \mathrm{mg} / \mathrm{kg}$ ). Four groups were then constituted, control groups (CONT, $\mathrm{n}=8$ ), iron loading alone (IRON, $\mathrm{n}=8$ ), doxorubicin alone (DOX, $\mathrm{n}=8$ ) or the combination of iron and doxorubicin (IRON+DOX). At D30, all mice underwent echocardiography.

Figure 2. Cell viability assessed by XTT assay of (A) cancerous EMT-6 cells or (B) H9c2 cardiomyocytes incubated for $24 \mathrm{~h}$ in the presence of increasing concentrations of irondextran alone, or $(\mathrm{C})$ in combination with $1 \mu \mathrm{M}$ of doxorubicin for $20 \mathrm{~h}$ in EMT-6 cells or (D) in H9c2. Values are means \pm SEM. Differences among groups were assessed by oneway ANOVA with a Tukey test as the post-hoc analysis.

Figure 3. Iron content assessed by atomic absorption spectroscopy in (A) plasma expressed in mg/L, (B) myocardium, (C) liver and (D) epididymal fat expressed in mg/kg of wet tissue weight, assessed 20 days (D21) or 29 days (D30) after the beginning of daily injections of dextran/iron (15 mg/kg from D1-D20) followed by single i.p. injection of Doxorubicin (6 mg/kg at D21). Values are means \pm SEM. Differences were assessed using 2way ANOVA with a Tukey test as the post-hoc analysis. 
Figure 4. Left ventricular changes assessed by (A) $\Delta$ left ventricular ejection fraction (LVEF), (B) $\Delta$ left ventricular mass indexed to body weight (LVMI). LVEF and LVMI were calculated with 2-dimensional B-mode echocardiography images at baseline (D0), 20 days (D21) or 29 days (D30) after the beginning of daily injections of dextran/iron (15 mg/kg from D1-D20) followed by a single i.p. injection of Doxorubicin (6 mg/kg, D21). LVMI was used as a measure of cardiac hypertrophy. Values are mean \pm SEM. Differences among groups were assessed by 2-way ANOVA with a Tukey test as the post-hoc analysis.

Figure 5. Myocardial mRNA expression of (A) atrial natriuretic peptide (ANP), (B) brain natriuretic peptide (BNP) and (C) $\beta$-myosin heavy chain $(\beta M H C)$ related to that of hypoxanthine-guanine phosphoribosyltransferase (HPRT), in arbitrary units (AU), 20 days (D21) or 29 days (D30) after the beginning of daily injections of dextran/iron administration (15 mg/kg from D1-D20) followed by single i.p. injection of Doxorubicin (6 $\mathrm{mg} / \mathrm{kg}, \mathrm{D} 21)$. Values are means \pm SEM. Differences among groups were assessed by 2-way ANOVA with a Tukey test as the post-hoc analysis.

Figure 6. Myocardial oxidative stress. (A) Measurements of myocardial oxidative stress using ESR spectroscopy with $\mathrm{CMH}$ as a spin probe, converted to the $\mathrm{CP}^{\bullet}$ radical in the presence of reactive oxygen-nitrogen species RONS; (B) myocardial mRNA expression of (B) catalase, (C) extracellular superoxide dismutase (ecSOD) and (D) manganesesuperoxide dismutase (MnSOD) related to this of hypoxanthine-guanine phosphoribosyltransferase (HPRT), in arbitrary units (AU), 20 days (D21) or 29 days (D30) after the beginning of daily injections of dextran/iron (15 mg/kg from D1-D20) 
followed by a single i.p. injection of Doxorubicin (6 mg/kg, D21). Differences were assessed by 2-way ANOVA with a Tukey test as the post-hoc analysis. 
Table 1. Forward and reverse sequences of primers used for the amplification of mouse genes

\begin{tabular}{|c|c|c|}
\hline & Forward (5' to 3') & Reverse (5' to 3') \\
\hline HPRT & CTGGTGAAAAGGACCTCTCG & TGAAGTACTCATTATAGTCAAGGGCA \\
\hline ANP & GAGAAGATGCCGGTAGAAGA & AAGCACTGCCGTCTCTCAGA \\
\hline BNP & ATGGATCTCCTGAAGGTGCTG & GTGCTGCCTTGAGACCGAA \\
\hline$\beta M H C$ & GCCAACACCAACCTGTCCAAGTTC & GCCAACACCAACCTGTCCAAGTTC \\
\hline Catalase & GATGAAGCAGTGGAAGGAGC & ACCACATCCTGAACGAGGAG \\
\hline ecSOD & CTGCTCGCTCACATAACAGC & ATGGCTGAGGTTCTCTGCAC \\
\hline MnSOD & AACTCAGGTCGCTCTTCAGC & GCTTGATAGCCTCCAGCAAC \\
\hline$\alpha B$-cristallin & GTTCTTCGGAGAGCACCTGTT & GAGAGTCCGGTGTCAATCCAG \\
\hline Hsp20 & GCCCGGATGAACACGGATT & CAGGTGGTGACGGAAGTTGG \\
\hline Hsp27 & CCCACCСТCTATCACGGCTA & ATCTGGGGTAAAGTGGCTCAC \\
\hline Hsp70 & CCGCCTACTTCAACGACTC & TCTTGAACTCCTCCACGAAG \\
\hline Hsp90B & GTCCGCCGTGTGTTCATCAT & GCACTTCTTGACGATGTTCTTGC \\
\hline
\end{tabular}


Table 2. Echocardiographic measurements

\begin{tabular}{|c|c|c|c|c|c|c|c|c|}
\hline & \multicolumn{4}{|c|}{ Baseline (Day 0): Before treatment } & \multicolumn{4}{|c|}{ Day 30: After treatment } \\
\hline & CONT & DOX & IRON & DOX-IRON & CONT & DOX & IRON & DOX-IRON \\
\hline$n$ & 8 & 8 & 8 & 8 & 8 & 8 & 8 & 8 \\
\hline HR, bpm & $433 \pm 86$ & $405 \pm 86$ & $413 \pm 49$ & $429 \pm 71$ & $387 \pm 43$ & $393 \pm 39$ & $415 \pm 51$ & $413 \pm 61$ \\
\hline LVEF, \% & $60 \pm 4$ & $62 \pm 5$ & $58 \pm 6$ & $63 \pm 9$ & $57 \pm 3$ & $44 \pm 7 \quad \dagger * \#$ & $58 \pm 8$ & $51 \pm 5 \dagger$ \\
\hline LVFS, \% & $32 \pm 2$ & $33 \pm 3$ & $31 \pm 4$ & $34 \pm 7$ & $30 \pm 2$ & $22 \pm 4 \dagger * \#$ & $30 \pm 5$ & $26 \pm 3 \dagger$ \\
\hline LVEDD, mm & $3.76 \pm 0.21$ & $3.67 \pm 0.35$ & $3.90 \pm 0.21$ & $3.87 \pm 0.29$ & $4.03 \pm 0.28$ & $4.06 \pm 0.25 \dagger$ & $4.07 \pm 0.29$ & $4.08 \pm 0.42$ \\
\hline LVMI, mg/g & $3.19 \pm 0.35$ & $2.87 \pm 0.47$ & $3.16 \pm 0.29$ & $3.37 \pm 0.24$ & $3.36 \pm 0.32 \#$ & $3.2 \pm 0.40 \#$ & $3.97 \pm 0.46 \dagger$ & $3.47 \pm 0.14 \#$ \\
\hline E wave & $539 \pm 144$ & $712 \pm 168$ & $680 \pm 201$ & $691 \pm 91$ & $675 \pm 110$ & $779 \pm 125$ & $848 \pm 289$ & $925 \pm 647$ \\
\hline A wave & $365 \pm 56$ & $462 \pm 111$ & $381 \pm 107$ & $408 \pm 70$ & $424 \pm 86$ & $472 \pm 92$ & $453 \pm 214$ & $605 \pm 604$ \\
\hline E/A ratio & $1.70 \pm 0.17$ & $1.66 \pm 0.35$ & $2.0 \pm 0.50$ & $1.72 \pm 0.24$ & $1.58 \pm 0.14$ & $1.78 \pm 0.39$ & $1.97 \pm 0.31$ & $1.76 \pm 0.41$ \\
\hline Tei index & $0.63 \pm 0.08$ & $0.71 \pm 0.16$ & $0.72 \pm 0.13$ & $0.86 \pm 0.20$ & $0.82 \pm 0.13$ & $0.82 \pm 0.13$ & $0.88 \pm 0.13$ & $0.90 \pm 0.16$ \\
\hline
\end{tabular}

Data are means \pm standard deviation. Bpm indicates beats per minute; HR: heart rate; LVEF: left ventricular ejection fraction; LVEDD: left ventricular end-diastolic diameter; LVFS: left ventricular fraction shortening; LVMI: left ventricular mass indexed to body weight; $n$ : number of mice. ; $\uparrow \mathrm{p}<0.01$ compared to baseline for each group * $\mathrm{p}<0.005$ compared to CONT group at day 30; \# $\mathrm{p}<0.05$ compared to IRON group at D30 using 2-way ANOVA for repeated measures with a Tukey test as the post-hoc analysis. 
Table 3. Myocardial relative mRNA expression of heat shock proteins after 21 days of iron loading

\begin{tabular}{ccc}
\hline Gene & CONT (D21) & IRON (D21) \\
\hline \hline$\alpha$ B-cristallin & $73.96 \pm 2.82$ & $119.81 \pm 26.85$ \\
Hsp20 & $41.49 \pm 2.37$ & $48.41 \pm 2.12 *$ \\
Hsp27 & $2.95 \pm 0.54$ & $2.47 \pm 0.06$ \\
Hsp70 & $0.17 \pm 0.03$ & $0.14 \pm 0.01$ \\
Hsp90B & $46.27 \pm 2.45$ & $48.69 \pm 1.94$ \\
\hline
\end{tabular}

* $\mathrm{p}=0.05$ compared to the CONT group 